\title{
Morfologi tulang belakang (ossa vertebrae) ikan keureling, Tor tambroides (Bleeker, 1854)
}

\author{
[The morphology of Thai mahseer's Tor tambroides (Bleeker, 1854) axial skeleton (ossa \\ vertebrae)]
}

\author{
Ilham Zulfahmi ${ }^{1 \bowtie}$, Yusrizal Akmal ${ }^{2}$, Agung Setia Batubara ${ }^{3}$ \\ ${ }^{1}$ Program Studi Biologi, Fakultas Sains dan Teknologi, Universitas Islam Negeri Ar-Raniry \\ Jalan Syeikh Abdul Rauf, Darussalam, Banda Aceh, 23111 \\ ${ }^{2}$ Program Studi Budidaya Perairan. Fakultas Pertanian, Universitas Almuslim \\ Jalan Almuslim, Matang Glumpang Dua, Peusangan, Kabupaten Bireuen, Aceh 24261 \\ ${ }^{3}$ Program Studi Budidaya Perairan, Fakultas Kelautan dan Perikanan, Universitas Syiah Kuala \\ Jalan Teuku Nyak Arief, Darussalam, Banda Aceh, Aceh, 23111
}

Diterima: 29 Januari 2018; Disetujui: 22 Mei 2018

\begin{abstract}
Abstrak
Penelitian ini bertujuan untuk mendeskripsikan morfologi tulang belakang (ossa vertebrae) ikan keureling, Tor tambroides (Bleeker, 1854). Contoh ikan diperoleh dari pedagang ikan di wilayah sungai Tangse Kabupaten Pidie dengan bobot $5 \mathrm{~kg}$ dan panjang $65 \mathrm{~cm}$. Tahapan pembuatan preparat tulang belakang dilakukan di Laboratorium Matematika dan Ilmu Pengetahuan Alam, Universitas Al Muslim Kabupaten Bireuen. Identifikasi terminologi tulang belakang ikan dilakukan di Laboratorium Terpadu Biologi, Program studi Biologi, Fakultas Sains dan Teknologi, Universitas Islam Negeri Ar-Raniry. Pembuatan preparat tulang belakang dilakukan secara fisik dan kimiawi. Tulang belakang yang telah bersih dirangkai menjadi satu kesatuan untuk dianalisis setiap bagian-bagiannya. Pemotretan setiap bagian tulang belakang dilakukan dengan menggunakan kamera Canon EOS 700D dan diolah dengan menggunakan Adobe Photoshop CS3. Penamaan setiap bagian tulang belakang dilakukan dengan cara membandingkan kemiripan bentuk dan letak dari setiap bagian tulang belakang ikan yang telah diteliti sebelumnya, baik dari famili yang sama maupun dari famili yang berbeda. Hasil penelitian menunjukkan ikan keureling memiliki empat buah tulang axial vertebrae yang termasuk dalam tulang Weber (Weberian apparatus), 19 ossa abdminal vertebrae, 18 pasang ossa costae, 16 ossa caudal vertebrae dan satu os urostyles vertebrae.
\end{abstract}

Kata penting: ikan keureling, ossa abdominal vertebrae, ossa caudal vertebrae, tulang Weber

\begin{abstract}
This study aims to describe the axial skeleton morphology (ossa vertebrae) of Thai mahseer's,Tor tambroides (Bleeker 1854). A $5 \mathrm{~kg}$ of $65 \mathrm{~cm}$ fish sample were obtained from fish trader in the Tangse River area of Pidie district.. The axial skeleton preparations processed at the Laboratory of Mathematics and Natural Sciences, Al Muslim University, Bireuen district. The identification of terminology was done at Integrated Biology Laboratory, Biology Department, Faculty of Science and Technology, Ar-Raniry Islamic State University. The keureling's axial skeleton processed by physically and chemically.. Axial skeleton was arranged into a single piece to analyze every part of it. Every part of axial skeleton documented by using Canon EOS 700D camera and processed by Adobe Photoshop CS3. The labeling of each part of the axial skeleton was done by comparing the similarity of the shape and location of each part of the fish axial skeleton that has been studied previously, either from the same family or from the different family. The results showed that Keureling had four axial vertebrae bones belonging to the weberian apparatus, 19 ossa abdominal vertebrae, 18 pairs ossa costales, 16 ossa caudal vertebrae and one os urostyles vertebrae.
\end{abstract}

Keywords: ossa abdominal vertebrae, ossa caudal vertebrae, Thai mahseer's, Weberian apparatus

\section{Pendahuluan}

Ikan dideskripsikan memiliki struktur morfologi tulang rangka yang kompleks dan sangat kinetik (Ferry-Graham \& Lauder 2001).

$\triangle$ Penulis korespondensi

Alamat surel: ilhamgravel@yahoo.com
Sistem musculoskeletal tengkorak ikan teleost dewasa diketahui terdiri atas sekitar 60 bagian tulang yang saling berhubungan (Aerts 1991). Perkembangan dan pertumbuhan tulang rangka terutama tulang belakang (ossa vertebrae) merupakan faktor penting pendukung kesehatan ikan. Tulang belakang berperan sebagai biomekanik 
penahan otot, fleksibilitas, dan elastisitas selama ikan bergerak (Webb 1975). Selain itu, tulang belakang juga merupakan lokus penting penyimpan mineral serta ikut berperan dalam pengaturan fosfor homeostasis (Skonberg et al. 1997).

Kajian morfologi tulang rangka ikan bertujuan untuk memahami hubungan taksonomik dan filogenetik antarspesies ikan (Mafakheri et al. 2015; Jalili et al. 2015). Disamping itu, kajian ini juga dibutuhkan sebagai langkah pencegahan dalam menganalisis keabnormalan sistem tulang rangka (Deschamps \& Sire 2010). Keabnormalan tulang rangka ikan merupakan dampak dari kelainan genetik, patologis, dan fisiologis yang berhubungan dengan faktor lingkungan. Kekurangan mineral (terutama fosfor) di perairan merupakan salah satu penyebab terjadinya keabnormalan tulang rangka. Keabnormalan tulang rangka umumnya muncul pada tahap perkembangan awal ikan (Cahu et al. 2003; Lall \& LewisMcCrea 2007), dan semakin memburuk pada tahap pertumbuhan menuju dewasa (Witten et al. 2006).

Ikan keureling, Tor tambroides (Bleeker 1854) (Gambar 1) merupakan salah satu ikan air tawar terbesar di Aceh, mencapai hingga 30-45 kg (Muchlisin et al. 2015). Ikan ini termasuk kedalam kelompok siprinid air tawar penting di wilayah Indonesia dan Malaysia. Umumnya ikan ini mendiami sungai berarus deras, serta memiliki sebaran luas terutama di Asia Tenggara (Arifin et al. 2015). Analisis isi lambung menunjukkan bahwa ikan keureling termasuk ke dalam golongan omnivora dengan proporsi makanan utama berupa alga hijau dan cacing tanah, sedangkan analisis hubungan panjang bobot menunjukkan bahwa ikan ini memiliki pola pertumbuhan allometrik negatif (Muchlisin et al. 2015).

Tingginya laju ekploitasi terhadap ikan keureling, membuat populasinya semakin menurun. Nelayan setempat dari Kabupaten Nagan Raya dan Aceh Barat menyatakan bahwa sangat sulit untuk menemukan ikan keureling berukuran besar selama dasawarsa terakhir (Muchlisin et al. 2015). Singh (2007) menyatakan bahwa populasi ikan genus Tor ini, sedang berada dalam kategori terancam akibat eksploitasi berlebihan, pencemaran perairan, dan gangguan ekologis. Pendapat senada juga diungkapkan melalui penelitian Ogale (2001) yang melaporkan bahwa populasi genus Tor di India telah menurun baik dalam jumlah dan ukuran serta berada di ambang bahaya kepunahan yang serius akibat lebih tangkap dan pencemaran perairan. Saat ini, ikan keureling terdaftar sebagai biota yang terancam punah dan berada dalam daftar merah International Union for Conservation of Nature (IUCN, 1990).

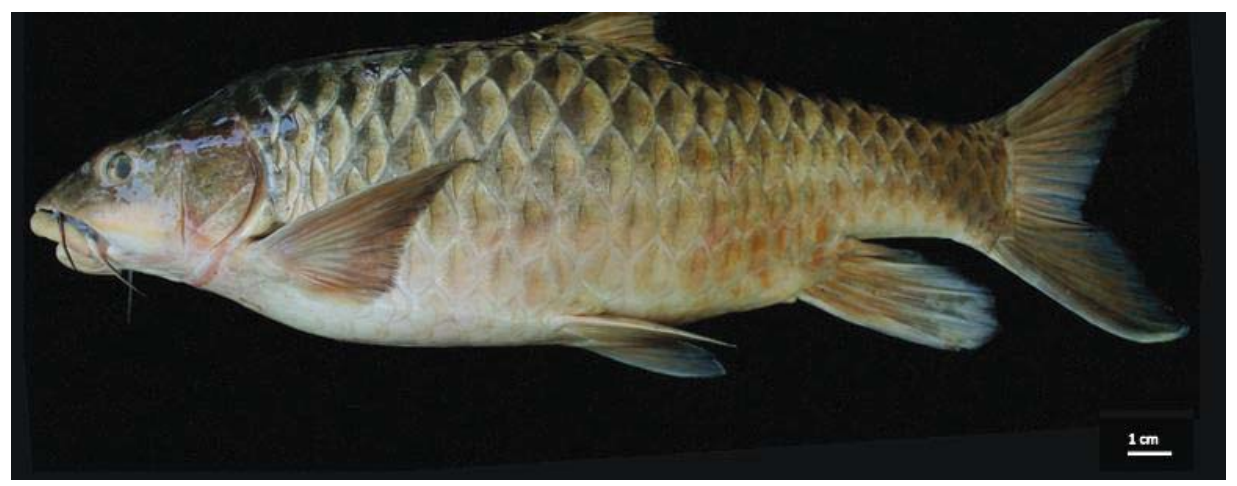

Gambar 1. Ikan keureling, Tor tambroides (Bleeker 1854), Skala bar: $1 \mathrm{~cm}$ 
Sampai saat ini, kajian morfologi tulang rangka pada ikan masih minim dilakukan jika dibandingkan dengan mamalia dan unggas (Leprevost \& Sire 2014). Mayoritas penelitian terhadap ikan keureling masih berkaitan dengan bidang ekologi dan upaya domestikasi (Muchlisin et al. 2015), sedangkan kajian morfologi tulang rangka ikan keureling masih belum ditemukan. Penelitian ini dilaksanakan dengan tujuan mendeskripsikan morfologi tulang belakang (ossa vertebrae) ikan keureling Tor tambroides (Bleeker, 1854).

\section{Bahan dan metode}

Penelitian ini dilaksanakan mulai bulan Oktober sampai dengan Desember 2017. Tahapan penelitian meliputi penyiapan contoh ikan, pembuatan preparat, dan identifikasi terminologi tulang belakang ikan. Tahapan pembuatan preparat tulang belakang dilakukan di Laboratorium Matematika dan Ilmu Pengetahuan Alam, Universitas Almuslim, sedangkan identifikasi terminologinya dilakukan di Laboratorium Terpadu Biologi, Program Studi Biologi, Fakultas Sains dan Teknologi, Universitas Islam Negeri ArRaniry.

Ikan keureling, Tor tambroides (Bleeker, 1854) yang digunakan pada penelitian ini diperoleh dari pedagang ikan di wilayah Sungai Tangse Kabupaten Pidie, Provinsi Aceh. Contoh ikan memiliki bobot $5 \mathrm{~kg}$ dengan panjang total $65 \mathrm{~cm}$. Jumlah ikan yang berhasil dikoleksi sebanyak satu ekor dalam keadaan mati segar untuk selanjutnya diangkut ke laboratorium.

\section{Pembuatan preparat tulang belakang ikan}

Pembuatan preparat tulang belakang dilakukan secara fisik dan kimiawi. Tahapan fisik diawali dengan meletakkan ikan keureling dengan posisi kepala di kiri dan ekor di kanan. Sisik ikan dihilangkan dengan menggunakan pisau atau pinset. Otot dan sisik ikan disiram dengan air panas, sehingga melepuh dan bewarna putih matang. Penyiraman air panas dilakukan secara perlahan agar tulang tidak rapuh. Otot pada tubuh ikan dibersihkan dengan pinset dan pisau. Sisa daging pada tulang ikan dibersihkan dengan menggunakan sikat halus.

Tahapan kimiawi diawali dengan merendam preparat tulang rangka ke dalam formalin $10 \%$ selama tujuh hari. Hal ini bertujuan agar tidak terjadi perbusukan pada tulang-tulang rawan. Selanjutnya dilakukan perendaman dalam larutan etanol 100\% selama 24 jam guna menghilangkan air dan sisa lemak yang melekat pada preparat tulang rangka (Taylor \& Van Dyke 1985). Preparat tulang rangka hasil pengawetan dijemur di bawah sinar matahari selama tujuh hari. Setelah melewati proses penjemuran, tulang rangka akan bewarna putih dan kaku. Pembersihan preparat tulang rangka dilakukan menggunakan sikat berbulu halus untuk kemudian dilapisi dengan cat spray pilox clear transparan dan dijemur kembali selama tiga hari. Apabila ada potongan tulang yang terlepas, ditempel dengan menggunakan perekat pada sendi asalnya. Preparat tulang rangka dimasukkan ke dalam wadah, diikat, dan direkat agar tidak lepas. Tulang-tulang belakang dipisahkan dari rangka utama untuk dianalisis lebih lanjut.

\section{Identifikasi terminologi tulang belakang}

Tulang belakang yang telah bersih dirangkai menjadi satu kesatuan untuk dianalisis setiap bagian-bagiannya. Tulang belakang dipilah menjadi tiga bagian utama yaitu bagian depan (ossa axial vertebrae), bagian abdominal (ossa abdominalis vertebrae), dan bagian kaudal (ossa caudal vertebrae). Penamaan setiap bagian tulang belakang dilakukan dengan cara membandingkan kemiripan bentuk dan letak setiap bagi- 
an tulang belakang ikan yang telah diteliti sebelumnya, baik dari famili yang sama (Howes 1982, Jalili et al. 2015) maupun dari famili yang berbeda (Rojo 1991, Diogo 2008). Pemotretan setiap bagian tulang belakang dilakukan dengan menggunakan kamera Canon EOS 700D. Gambar yang diperoleh diolah dengan menggunakan Adobe Photoshop CS3. Semua hasil pengamatan dianalisis secara deskriptif dan disajikan dalam bentuk gambar.

\section{Hasil}

Ikan keureling memiliki empat tulang axial vertebrae yang termasuk dalam tulang $\mathrm{We}$ ber (Weberian apparatus), 19 ossa abdominal vertebrae, 18 pasang ossa costae, 16 ossa caudal vertebrae, dan satu os urostyles vertebrae (Gambar 2).

\section{Ossa axial vertebrae}

Ossa axial vertebrae pada ikan keureling terdiri atas vertebrae centrum 1- 4 tulang. Di bagian cranial akan membentuk persendian dengan condylus occipitalis dari os cranium. Di bagian caudal, tulang ini bersendi dengan os centrum kedua dan akan membentuk tulang Weber yang terdiri atas empat tulang pembentuk yaitu ossa tripus, ossa intercalarium, ossa scaphium, dan ossa claustrum (Gambar 3).

Centrum pertama memiliki ukuran yang lebih pendek dibandingkan centrum kedua. Centrum ketiga berbentuk memanjang dan membesar, yang berfungsi untuk menopang articularis tripus dan arcus neural. Centrum vertebrae kedua dan ketiga tidak menyatu. Bagian centrum lateral kedua umumnya meluas ke bagian bawah luar kemudian melengkung ke bagian depan tripus.

Os tripus terletak di bagian caudal aparatus weberian dan masih termasuk dalam axial vertebrae. Os tripus terletak di sisi lateral-ventral vertebrae dari os centrum kedua yang bagian dorsalnya memiliki ujung memanjang ke bagian caudal dari os costae pleura dari centrum keempat. Os tripus berasal dari parapophisis os costae pleura dan terletak di centrum ketiga yang berhubungan ligamen dengan gelembung renang. Os tripus ikan keureling berbentuk panjang, tipis,

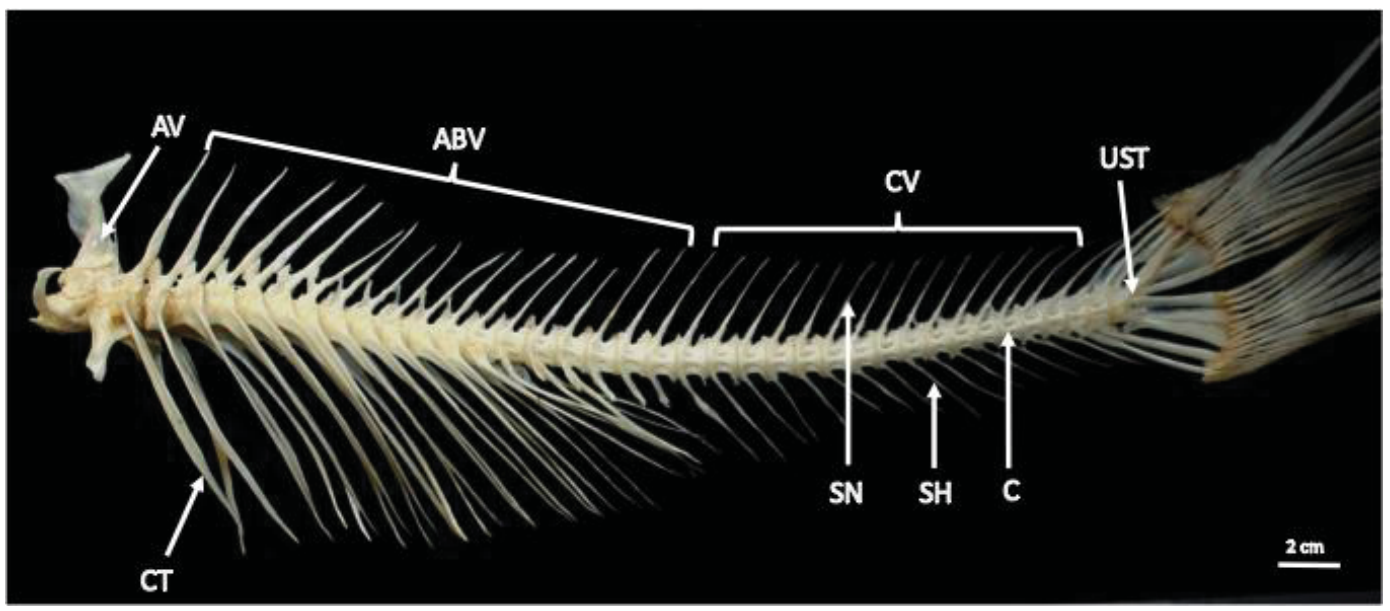

Gambar 2. Struktur ossa vertebrae ikan keureling. AV: axial vertebrae, ABV: abdominalis vertebrae, CV: caudal vertebrae, CT: costae, UST: urostyles, SN: spinal neural, SH: spinal haemal, C: centrum; Skala bar: $2 \mathrm{~cm}$ 


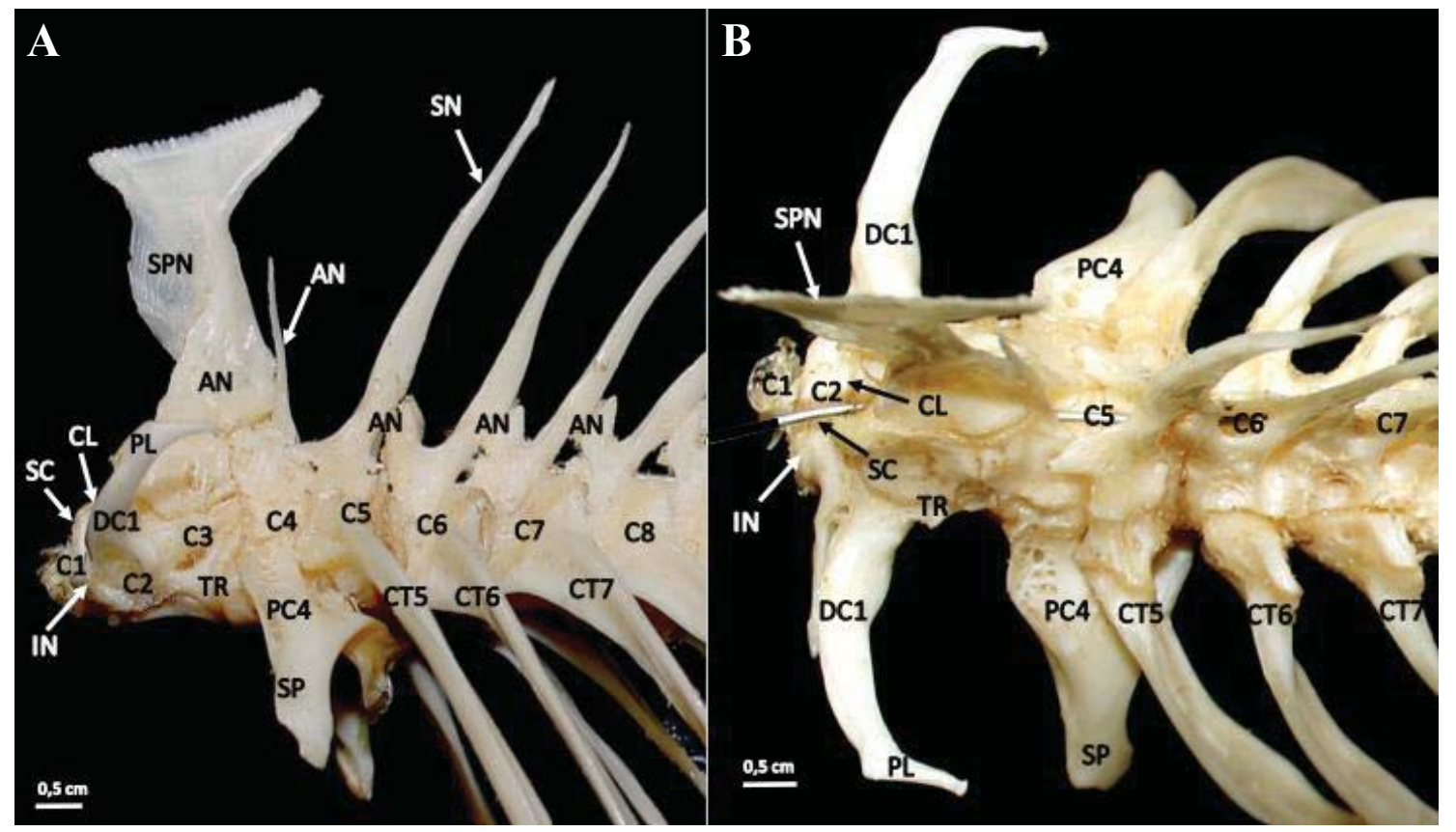

Gambar 3. A Ossa axial vertebrae dan ossa abdominalis vertebrae tampak lateral (kiri), B ossa axial vertebrae dan dan ossa abdominalis vertebrae tampak dorsal (kanan). SPN: supraneural, AN: arcus neural, DC: dorsal costae, PL: processus lateralis, SC: scaphium, IN: intercalarium, TR: tripus, SP: suspensorium, CL: claustrum, CT: costae, PC: pleura costae, C: centrum; Skala Bar: $0,5 \mathrm{~cm}$.

dengan bagian dasar medial melebar tegak lurus terhadap vertebare. Bagian lateral memiliki ujung menipis tajam dan berbentuk seperti pita. Os intercalarium berasal dari arcus neural kedua dan articularis processus dengan penekanan pada centrum kedua. Os intercalarium berbentuk huruf $\mathrm{T}$ dan menempel pada os tripus dan os scaphium melalui ligamen scaphiaintercalar dan interalotripodal.

Os scaphium dan os claustrum adalah bagian tulang Weber yang terletak pada anterior. Os scaphium dan os claustrum berasal dari arcus neural pertama dan membentuk lubang anterior canalis neuralis di mana terdapat ligamen dari os scaphium yang membesar dan memanjang di bagian posterior. Os clastrum terletak pada bagian dorsal dari os scaphium dan saling bertautan satu sama lain melalui ligamen clastroscaphial. Os supraneural ikan keureling terlihat jelas, lebih besar dan tipis serta menyatu pada bagian dorsal.
Posterior os supraneural menyatu menyerupai bentuk mangkuk pada permukaan dorsal, akan tetapi tidak menyatu dengan spinaneural (Gambar 3).

Ossa abdominalis vertebrae

Ossa abdominalis vertebrae mempunyai persendian yang kokoh satu dengan lainnya dan dibentuk diantara anterior dan posterior centrum. Di bagian kedua sisi lateral centrum terdapat 18 pasang ossa costae serta tiga pasang costae yang tidak berkembang (rudimenter) yaitu costae pertama sampai ketiga. Arcus neural pertama ikan keureling telah termodifikasi menjadi os scaphium dan os claustrum, sedangkan arcus neural yang kedua termodifikasi menjadi os intercalarium. Arcus neural dari centrum ketiga dan keempat juga terlihat mengalami pembesaran. Arcus neuralis dari centrum ketiga bagian anterior dan posterior menunjukkan lebih banyak 
variasi. Arcus neuralis berupa lengkungan yang mengarah ke bagian kaudal mulai terdapat pada centrum kelima. Di bagian ventral tidak terdapat arcus haemal (Gambar 4).

Ossa costae berfungsi sebagai pelindung organ-organ dan pembetukan rongga serta membentuk ruangan terbuka di daerah abdomen. Letak os costae dari anterior sampai ke posterior mengalami perpanjangan dan cenderung lebih miring ke belakang (Gambar 4). Os costae bersendi dengan ossa abdominalis vertebrae pada bagian facies articularis.

Os suspensorium adalah os costae keempat yang telah termodifikasi dan berfungsi sebagai tautan gelembung renang anterior bagian dorsal. Pada ikan keureling, os suspensorium terlihat jelas dari lateral maupun dorsal tanpa menghilangkan kerangka bagian atas os suspensorium yang berfungsi sebagai tempat melekatnya tendon atau otot yang berhubungan dengan gelembung renang (Gambar 3). Bentuk os costae ke lima lebih ramping/tipis, kokoh dan besar sedangkan os costae ke 17 memiliki bentuk menyerupai silindris, lentur dan pendek serta berhubungan langsung dengan parapofisis centrum.
Ossa caudal vertebrae dan os urostyles vertebrae

Ikan keureling memiliki 16 ossa caudal vertebrae dimulai dari centrum ke 24. Ossa caudal vertebrae merupakan rangkaian tulang pelvis dan kemudi yang pendek tetapi sangat kokoh serta saling terhubung kuat. Ossa caudal vertebrae memiliki arcus neural, spina neural, dan spina haemal.

Arcus neuralis terletak di bagian dorsal dari centrum. Spina neural dari anterior sampai ke posterior mengalami perpanjangan dengan bentuk lebih miring ke belakang. Arcus neural anterior terlihat membesar dibandingkan dengan posterior. Arcus neural ini, menopang tulang spina neural yang semakin pendek dan mengecil. Spina neural terbentuk dari dasar arcus neural. Spina haemal terletak di bagian ventral dari centrum dengan canal haemal yang terlihat jelas sebagai tempat lewatnya pembuluh darah. Pada bagian posterior, canal neural dan canal haemal memiliki bentuk yang semakin mengecil dibandingkan pada bagian anterior (Gambar 5).

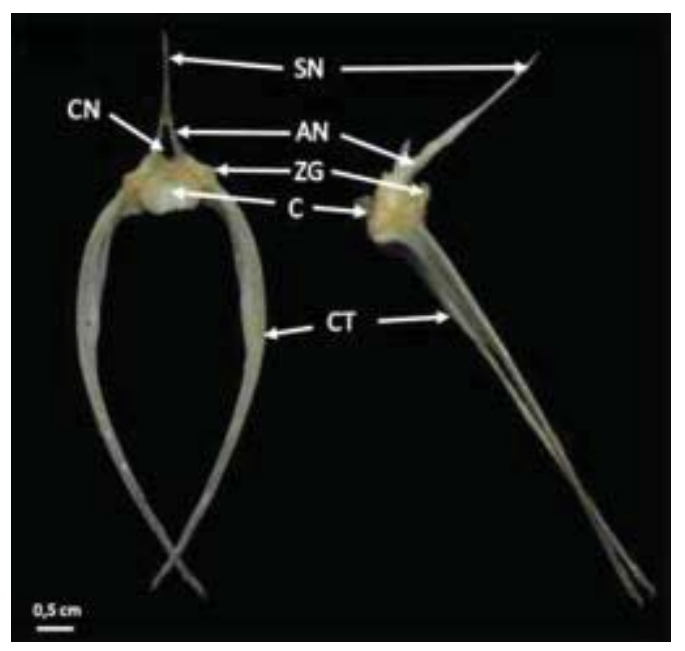

Gambar 4. Os abdominal vertebrae ketujuh, sebelah kanan tampak lateral dan kiri tampak caudal. SN: spinal neural; AN: arcus neural; CN: canal neural; ZG: zygopophysis; C: centrum. Skala bar: $0,5 \mathrm{~cm}$. 

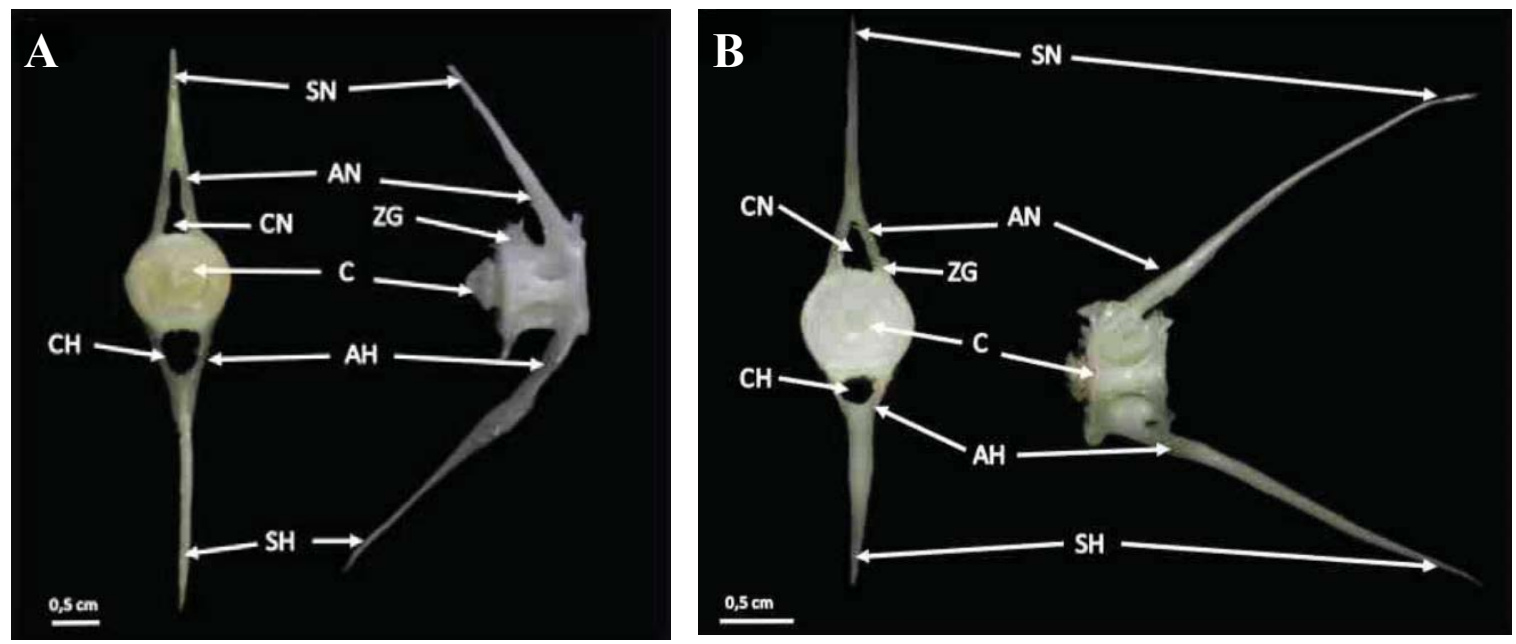

Gambar 5. Os caudal vertebrae ke 1, sebelah kanan tampak lateral dan kiri tampak cranial (A). Os caudal vertebrae ke 16, sebelah kanan tampak lateral dan kiri tampak cranial (B). SN: spinal neural; $\mathrm{AN}$ : arcus neural; $\mathrm{CN}$ : canal neural; ZG: zygopophysis; $\mathrm{AH}$ : arcus haemal; $\mathrm{CH}$ : canal haemal; SH: spina haemal; C: centrum. Skala bar: $0,5 \mathrm{~cm}$.

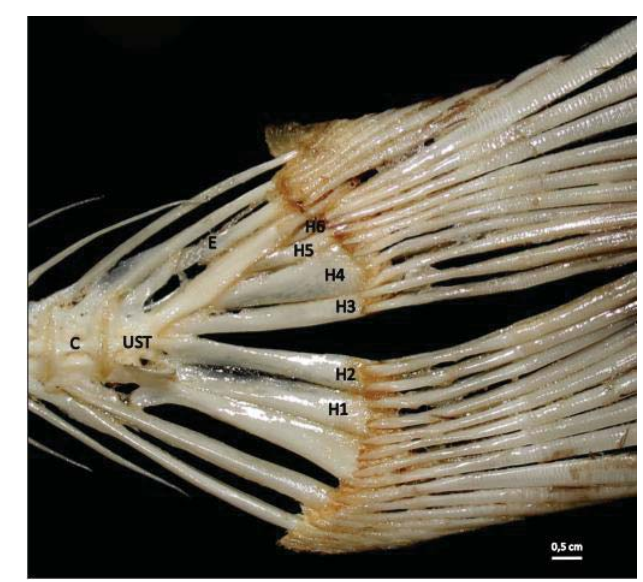

Gambar 6. Os urostyle vertebrae tampak lateral. UST: urostyles; C: centrum; H: hypural; E: epural. Skala bar: $0,5 \mathrm{~cm}$.

Os urostyles vertebrae ikan keureling terletak pada centrum terakhir dengan posisi mengarah ke dorsokaudal serta miring ke belakang. Pada bagian dasar dari os urostyle vertebrae melekat empat ossa hypural yaitu os hypural 3, 4, 5 dan 6. Pada bagian atas dari os urostyle vertebrae melekat os epural dengan arah yang sejajar. Os urostyles vertebrae memiliki ukuran yang lebih tebal dibandingkan dengan ossa hypural dan os epural (Gambar 6).

\section{Pembahasan}

Pengetahuan mengenai morfologi tulang rangka diperlukan guna memahami hubungan antara taksonomi dan filogenetik ikan (Diogo \& Bills 2006, Keivany 2014) serta membantu upaya deteksi dan pencegahan terjadinya keabnormalan pada tulang ikan (Zhang et al. 2012). Infomasi morfologi tulang rangka juga dapat digunakan untuk mendeskripsikan ontogeni ikan mulai dari awal perkembangannya hingga dewasa serta menilai sejauh mana evolusi terjadi (Adriaens et al. 
2001). Selain itu Leprevost \& Sire (2014) menyebutkan bahwa profil morfologi ossa vertebrae yang dimiliki ikan sangat memengaruhi kecepatan dan gaya renang ikan tersebut.

Ikan keureling memiliki empat tulang axial vertebrae yang termasuk kedalam tulang Weber (Weberian apparatus), 19 abdominalis vertebrae, 16 caudal vertebrae dan satu os urostyle vertebrae. Sanger \& McCune (2002) menyebutkan bahwa bentuk tulang Weber ikan keureling yang terdiri atas os tripus, os intercalarium, os scaphium dan os claustrum identik dengan karakteristik ikan famili Cyprinidae. Selain itu, tulang Weber ikan keureling memiliki jumlah yang sama dengan ikan-ikan famili Cyprinidae lainnya (Jalili et al. 2015, Nasri et al. 2016). Walaupun demikian, ikan keureling dan Cyprinion milesi cenderung memiliki bentuk supraneural yang lebih serupa dibandingkan dengan Barbus cyri. Menurut Bird \& Hernandez (2007), tulang Weber berhubungan langsung dengan gelembung renang dan pendengaran bagian dalam, di mana variasi interspesifik antarbeberapa famili seperti Balitoridae, Gyrinocheilidae, dan Catostomidae terlihat lebih sedikit berbanding pada famili Cyprinidae dan Cobitidae.

Ossa costae pada ikan keureling memiliki bentuk yang berbeda dengan ikan-ikan famili lainnya. Ossa costae mengalami perpanjangan dan cenderung lebih miring ke belakang dengan lengkungan tulang yang sempurna. Hal ini berbeda dengan ikan famili Acipenseridae yang tidak memiliki lengkung tulang rusuk sempurna (Leprevost \& Sire 2014). Menurut Takeuchi \& Hosoya (2011), lengkungan ossa costae pada ikan sangat dipengaruhi oleh kapasitas rongga abdominal dan gaya renang ikan. Ikan dengan tubuh ramping memanjang cenderung tidak memiliki lengkungan ossa costae yang sempurna dibandingkan dengan ikan bertubuh lebar. Terda- pat 18 ossa costae dan tiga costae yang mengalami rudimenter atau tidak berkembang yaitu pada costae pertama sampai dengan ketiga. Terjadinya rudimenter diduga berkaitan dengan posisi gelembung renang yang berada di bawah centrum pertama sampai ke empat, sehingga dibutuhkan ruang yang cukup untuk mengatur keseimbangan saat berenang. Walaupun demikian dibutuhkan penelitian lanjutan untuk membuktikan hal tersebut.

Ikan keureling memiliki 19 ossa abdominal vertebrae, dengan jumlah keseluruhan ossa vertebrae mencapai 40. Jumlah ossa abdominal vertebrae dan keseluruhan ossa vertebrae ikan keureling relatif tidak berbeda dengan ikan famili Cyprinidae lainnya. Jalili et al. (2015) menginformasikan bahwa ikan Cyprinion milesi dari famili Cyprinidae memiliki kisaran jumlah keseluruhan ossa vertebrae antara 42-44 yang terdiri atas 19-22 ossa abdominal vertebrae. Keserupaan morfologi ossa abdominal vertebrae ikan keureling dengan ikan jenis lain dari famili Cyprinidae terlihat pada bentuk arcus neural, spina neural, dan canal neural. Walaupun demikian terdapat perbedaan terhadap ukuran relatifnya bergantung kepada panjang dan tubuh ikan tersebut.

Dibandingkan dengan genus Priocharax (famili Characidae), ikan keureling memiliki jumlah total ossa vertebrae yang lebih tinggi. Genus Priocharax hanya memiliki jumlah total ossa vertebrae antara 33-35 dengan jumlah ossa abdominal vertebrae berkisar antara 14-15 (Mattox et al. 2016). Sebaliknya apabila dibandingkan dengan genus Cryptacanthodes (famili Cryptacanthodidae) dan famili Zaproridae, maka ikan keureling memiliki jumlah total ossa vertebrae dan ossa abdominal vertebrae yang lebih rendah. Schnell \& Hilton (2014) menyebutkan bahwa jumlah ossa abdominal vertebrae genus 
Cryptacanthodes berkisar antara 32-33 dengan jumlah total ossa vertebrae mencapai 85-88. Ikan famili Zaproridae memiliki jumlah ossa abdominal vertebrae antara 25-27 dengan total jumlah ossa vertebrae mencapai 61-63 (Hilton \& Stevenson 2013). Secara morfologis, perbedaan antara ossa abdominal vertebrae famili Cyprinidae dan famili Hiodontidae terlihat dari ada tidaknya zygopophysis, parapophysis, dan epineural. Famili Cyprinidae memiliki zygopophysis yang terletak di bagian dorsokaudal dari centrum, akan tetapi tidak memiliki parapophysis dan epineural; sedangkan famili Hiodontidae tidak memiliki zygopophysis, akan tetapi memiliki parapophysis yang terletak di bagian ventral dari centrum serta epineural yang terletak di bagian lateral dari arcus neural (Hilton, 2002).

Meskipun dalam famili yang sama (Cyprinidae), ikan keureling memiliki jumlah ossa caudal vertebrae yang lebih tinggi daripada Pethia setnai dengan 13 ossa caudal vertebrae (Katwate et al. 2013) dan lebih rendah berbanding genus Paedocypris yang memiliki 21-23 ossa caudal vertebrae (Britz \& Conway 2009). Akan tetapi jumlah ossa caudal vertebrae ikan keureling relatif sama apabila dibandingkan dengan jumlah ossa caudal vertebrae Barboides gracilis dan $B$. britzi (Cyprinidae) yaitu berkisar antara 17-19 (Conway et al. 2017).

Ikan keureling memiliki jumlah ossa caudal vertebrae lebih rendah berbanding genus Priocharax (famili Characidae) yang memiliki 1921 ossa caudal vertebrae (Mattox et al. 2016), spesies Zaprora silenus (Famili Zaproridae) yang memiliki 35-37 ossa caudal vertebrae (Hilton \& Stevenson, 2013) serta genus Cryptacanthodes (Famili Cryptacanthodidae) yang memiliki 53-55 ossa caudal vertebrae (Schnell dan Hilton, 2014). Os urostyles vertebrae ikan keureling memiliki bentuk yang serupa dengan ikan famili
Cyprinidae lainnya (Jalili et al. 2015) akan tetapi berbeda dengan ikan famili Percidae (Voskoboinikova \& Grechanov 2002). Perbedaan tersebut terletak pada jumlah ossa hypural yang melekat pada os urostyles vertebrae. Famili Percidae memiliki lima ossa hypural yang terpisah, tiga os epural serta memiliki bentuk os urostyles vertebrae yang memanjang dan meruncing ke arah kaudal, sedangkan ikan keureling memiliki enam ossa hypural yang terpisah, satu os epural serta memiliki os urostyles vertebrae lebih pendek.

Menurut Enghoff (1991), jumlah ossa vertebrae pada setiap famili ikan sangat dipengaruhi oleh bentuk morfologi, sifat hidup, umur, dan kemampuannya berevolusi. Ikan yang hidup pada perairan berarus deras umumnya memiliki jumlah ossa verterbrae yang lebih tinggi, dengan bentuk ossa costae yang lebih pendek dan tidak melengkung sempurna dibandingkan dengan ikan yang hidup pada perairan relatif tenang (Liem et al. 2001 dan Leprevost \& Sire 2014).

\section{Simpulan}

Ikan keureling memiliki empat axial vertebrae, 19 ossa abdominal vertebrae, 18 pasang ossa costae, 16 ossa caudal vertebrae dan satu os urostyles vertebrae. Ikan keureling memiliki keserupaan bentuk dan jumlah ossa vertebrae jika dibandingkan dengan famili sejenis (Cyprinidae), namun terdapat perbedaan dengan famili lainnya (Characidae, Cryptacanthodidae dan Zaproridae).

\section{Persantunan}

Ucapan terima kasih disampaikan kepada Lembaga Penelitian dan Pengabdian Masyarakat Universitas Islam Negeri Ar-Raniry yang telah mendanai penelitian ini melalui skema "Penelitian Pemula 2017”. 


\section{Daftar pustaka}

Adriaens D, Aerts P, Verraes W. 2001. Ontogenetic shift in mouth opening mechanisms in a catfish (Clariidae, Siluriformes): a response to increasing functional demands. Journal of Morphology, 247(3): $197-216$.

Aerts P. 1991. Hyoid morphology and movements relative to abducting forces during feeding in Astatotilapia elegans (Teleostei, Cichlidae). Journal of Morphology, 208(3): 323 - 345 .

Arifin OZ, Subagja J, Hadie W. Karakterisasi biometrik tiga populasi ikan semah Tor douronensis (Valenciennes, 1842) dalam mendukung konservasi sumber daya genetik. Jurnal Iktiologi Indonesia, 15(2): 143-154

Bird NC, Hernandez LP. 2007. Morphological variation in the weberian apparatus of Cypriniformes. Journal of Morphology, 268(9): 739 - 757.

Britz R, Conway KW. 2009. Osteology of Paedocypris, a miniature and highly developmentally Truncated Fish (Teleostei: Ostariophysi: Cyprinidae). Journal of Morphology, 270(4): 389 - 412.

Cahu CL, Zambonito IJL, Takeuchi T. 2003. Nutritional components affecting skeletal development in fish larvae. Aquaculture, $227(1-4): 254-258$

Conway KW, Kubicek KM, Britz R. 2017. Morphological novelty and modest developmental truncation in Barboides, Africa's smallest vertebrates (Teleostei: Cyprinidae). Journal of Morphology, 278(6): $750-764$.

Deschamps MH, Sire JY. 2010. Histomorphometrical studies of vertebral bone condition in farmed rainbow trout, Oncorhynchus mykiss. Journal of Applied Ichthyology, 26(2): 377-380.

Diogo R, Bills R. 2006. Osteology and myology of the cephalic region and pectoral girdle of the South African cat fish Austroglanis gilli, with comments on the autapomorphies and phylogenetic relationships of the Austroglanididae (Teleostei: Siluriformes). Animal Biology, 56(1): 39 $-62$.

Diogo R. 2008. The Origin of Higher Clades, Osteology, Myology, Phylogeny and
Evolution of Bony Fishes and the Rise of Tetrapods. Science Publishers. USA. $396 \mathrm{p}$.

Enghoff IB.1991. Mesolithic eel-fishing at Bjornsholm, Denmark, spiced with exotic species. Journal of Danish Archaeology, 10(1): 105-118.

Ferry-Graham LA, Lauder GV. 2001. Aquatic prey capture in ray-finned fishes: a century of progress and new directions. Journal of Morphology, 248(2): 99-119

Hilton EJ. 2002. Osteology of the extant North American fishes of the genus Hiodon Lesueur, 1818 (Teleostei: Osteoglossomorpha: Hiodontiformes). Fieldiana (Zoology) new series 100: 1-152.

Hilton EJ, Stevenson DE. 2013. Osteology of the Prowfish, Zaprora silenus (Cottiformes: Zoarcoidei: Zaproridae). Journal of Morphology, 274(10): 1143 - 1163.

Howes GJ. 1982. Anatomy and evolution of the jaws in the semiplotine carps with a review of the genus Cyprinion Heckel, 1843 (Teleostei: Cyprinidae). Bulletin of the British Museum (Natural History), Zoology, 42(4): 299 - 335.

IUCN. 1990. IUCN red list of threatened animal. IUCN, Gland and Cambrige.

Jalili P, Eagderi S, Nikmehr N, Keivany Y. 2015. Descriptive osteology of Barbus cyri (Teleostei: Cyprinidae) from southern Caspian Sea basin. Iranian Journal of Ichthyology, 2(2): $105-112$.

Katwate U, Paingankar MS, Jadhav S, Dahanukar N. 2013. Phylogenetic position and osteology of Pethia setnai (Chhapgar \& Sane, 1992), an endemic barb (Teleostei: Cyprinidae) of the Western Ghats, India, with notes on its distribution and threats. Journal of Threatened Taxa, 5(17): $5214-5227$.

Keivany Y. 2014. Comparative osteology of the suspensorial and opercular series in representatives of the eurypterygian fishes. Iranian Journal of Ichthyology, 1(2): 73-89.

Lall SP, Lewis-McCrea LM. 2007. Role of nutrients in skeletal metabolism and pathology in fish: an overview. Aquaculture, 267(1): 3 - 19 .

Leprevost A, Sire JY. 2014. Architecture, mineralization and development of the axial 
skeleton in Acipenseriformes, and occurrences of axial anomalies in rearing conditions; can current knowledge in teleost fish help? Journal of Applied Ichthyology, 30(4): $767-776$.

Liem K, Bemis W, Walker WF, Grande L. 2001. Chapter 8: The postcranial skeleton: The axial skeleton. In: Lewis $\mathrm{T}$ (ed.). Functional Anatomy of the Vertebrates: An Evolutionary Perspective. Emily Barrosse. Orlando. pp. 269-293.

Mafakheri P, Eagderi S, Farahmand H, MousaviSabet H. 2015. Osteological structure of Kiabi loach, Oxynoemacheilus kiabii (Actinopterygii: Nemacheilidae). Iranian Journal of Ichthyology, 1(3): 197205

Mattox GMT, Britz B, Piza MT. 2016. Osteology of Priocharax and remarkable developmental truncation in a miniature Amazonian Fish (Teleostei: Characiformes: Characidae). Journal of Morphology, 277(1): $65-85$.

Muchlisin ZA, Batubara AS, Siti-Azizah MN, Adlim M, Hendri A, NurFadli, Muhammadar AA, Sugianto S. 2015. Feeding habit and length weight relationship of keureling fish, Tor tambra Valenciennes, 1842 (Cyprinidae) from the western region of Aceh Province, Indonesia. Biodiversitas, 16(1): 89 - 94.

Nasri M, Eagderi S, Farahmand H. 2016. Descriptive and comparative osteology of Bighead Lotak, Cyprinion milesi (Cyprinidae: Cypriniformes) from southeastern Iran. Vertebrate-Zoology, 66(3): $251-260$.

Ogale SN. 2001. Mahseer breeding and conservation and possibilities of commercial culture, the Indian experience. In: Petr T, Swar SB (eds.). Cold Water Fisheries

in the trans-Himalayan Countries. FAO Fisheries Technical Paper 431. Rome. $38 \mathrm{p}$.

Rojo AL. 1991. Dictionary of Evolutionary Fish Osteology. CRC Press. 273 p.

Sanger TJ, McCune AR. 2002. Comparative osteology of the Danio (Cyprinidae: Ostariophysi) axial skeleton with comments on Danio relationships based on molecules and morphology. Zoological
Journal of the Linnean Society, 135(4): $529-546$.

Singh AK. 2007. Biological and reproductive diversity in reverie as well as lacustrine golden mahser, Tor putitora (Hamilton 1822) in central Malayas, India. In: Siraj SS, Christianus A, Kiat NC, De Silva SS. (eds.). Mahser, the Biology, Culture and Conservation. Proceeding of the International Symposium on the Mahseer. Malaysian Fisheries Society. Kuala Lumpur, Malaysia. pp 79 - 97.

Skonberg DI, Yogev L, Hardy RW, Dong FM. 1997. Metabolic response to dietary phosphorus intake in rainbow trout (Oncorhynchus mykiss). Aquaculture, 157(1): $11-24$.

Schnell NK, Hilton EJ. 2014. Osteology and ontogeny of the Wrymouths, Genus Cryptacanthodes (Cottiformes: Zoarcoidei: Cryptacanthodidae). Journal of Morphology, 276(6): 185 - 208.

Takeuchi H, Hosoya K. 2011. Osteology of Ischikauia steenackeri (Teleostei: Cypriniformes) with comments on its systematic position. Ichthyological Research, 58 (1): $10-18$.

Taylor WR, Van Dyke CC. 1985. Revised procedures for staining and clearing small fishes and other vertebrates for bone and cartilage study. Cybium 9 (2): 107-119.

Voskoboinikova OS, Grechanov IG. 2002. Development of the skeleton during the ontogenesis of the River Perch Perca fluviatilis. Journal of Ichthyology, 42 (4): 322 -333 .

Webb PW. 1975. Hydrodynamics and energetics of fish propulsion. Bulletin of the Fisheries Research Board of Canada, 190: 1-159.

Witten PE, Obach A, Huysseune A, Baeverfjord G. 2006. Vertebrae fusion in Atlantic salmon (Salmo salar): development, aggravation and pathways of containment. Aquaculture, 258(1-3): 164-172.

Zhang X, Shimoda K, Ura K, Adachi S, Takagi Y. 2012. Developmental structure of the vertebral column, fins, scutes and scales in bester sturgeon, a hybrid of beluga Huso huso and sterlet Acipenser ruthenus. Journal of Fish Biology, 81(6): 1985-2004 